\title{
Técnicas para superação da dormência de sementes de guanandi
}

\author{
Rosemeire Carvalho da Silva( ${ }^{(1)}$, Elisa Serra Negra Vieira ${ }^{(2)}$ e Maristela Panobianco(1)
}

\begin{abstract}
(1)Universidade Federal do Paraná, Departamento de Fitotecnia e Fitossanitarismo, Rua dos Funcionários, no 1.540, CEP 80035-050 Curitiba, PR, Brasil. E-mail: rosemeirecarvalhosilva@gmail.com, maristela@ufpr.br ${ }^{(2)}$ Embrapa Florestas, Estrada da Ribeira, Km 11, Caixa Postal 319, CEP 83411-000 Colombo, PR, Brasil. E-mail: elisa.vieira@embrapa.br
\end{abstract}

Resumo - O objetivo deste trabalho foi avaliar tipos de preparo de sementes de guanandi (Calophyllum brasiliense), com vistas à superação da dormência física e mecânica, e verificar a influência da temperatura e do substrato sobre a germinação. Foram avaliados três substratos (papel, areia e vermiculita), duas temperaturas de germinação $\left(25\right.$ e $\left.30^{\circ} \mathrm{C}\right)$ e quatro tipos de preparo das sementes: sementes íntegras; sementes nuas, sem tegumento e endocarpo; sementes com punctura no endocarpo, na região próxima ao eixo embrionário ou na região oposta ao eixo embrionário; e sementes cortadas a $1 / 3$ da região oposta ao eixo embrionário. Foram realizados testes de vigor (índice de velocidade de germinação e emergência de plântulas em campo), e a curva de embebição foi obtida para os diferentes tipos de preparo da semente. A retirada total do envoltório (endocarpo e tegumento) é necessária para a completa superação da dormência física e mecânica das sementes de guanandi. A germinação das sementes deve ser realizada em substrato papel à temperatura de $30^{\circ} \mathrm{C}$.

Termos para indexação: Calophyllum brasiliense, espécie nativa, germinação, madeira de lei, sementes recalcitrantes, testes laboratoriais.

\section{Techniques for overcoming dormancy in guanandi seeds}

\begin{abstract}
The objective of this work was to evaluate different types of preparation of guanandi (Calophyllum brasiliense) seeds, in order to overcome physical and mechanical dormancy, and to verify the effects of temperature and substrate on germination. Three substrates (paper, sand, and vermiculite), two germination temperatures $\left(25\right.$ and $\left.30^{\circ} \mathrm{C}\right)$, and four seed preparation types were evaluated: whole seeds; bare seeds, without testa and endocarp; seeds with punctured endocarp in the region near the embryonic axis or in the region opposite of the embryonic axis; and seeds cut at $1 / 3$ of the region opposite of the embryonic axis. Vigor tests were performed (index of germination speed and emergence of seedlings in the field), and the imbibition curve was obtained for the different types of seed preparation. Total wrap (endocarp and testa) withdrawal is necessary to completely overcome physical and mechanical dormancy of guanandi seeds. Seed germination should be held in paper substrate at a temperature of $30^{\circ} \mathrm{C}$.
\end{abstract}

Index terms: Calophyllum brasiliense, native species, germination, hardwood, recalcitrant seeds, laboratorial tests.

\section{Introdução}

A demanda por sementes e mudas de espécies nativas é crescente, tanto para a recomposição de áreas degradadas quanto para o reflorestamento. $\mathrm{O}$ guanandi (Calophyllum brasiliense Cambessedes) é uma espécie nativa do Brasil com ocorrência desde a região Amazônica até o norte de Santa Catarina. Trata-se de planta com alto potencial madeireiro e com boa possibilidade de cultivo, especialmente em áreas úmidas, com moderado excesso de água, próximas a cursos de água (Oliveira \& Joly, 2010; Schultz, 2011). A espécie também tem importância farmacêutica, por possibilitar a extração de metabólitos derivados de xantonas, cumarinas, flavonoides e terpenos, que têm ação antibacteriana, moluscicida, anti-hipertensiva e atividade contra imunodeficiência humana (HIV-1) (Noldin et al., 2006; Braga et al., 2007; BernabéAntonio et al., 2010; Carvalho et al., 2013).

O êxito na implantação de um projeto de produção de essências florestais nativas depende, em grande parte, da qualidade da semente para a produção de mudas. Assim, há, na literatura, uma grande quantidade de trabalhos que avaliam aspectos do processo germinativo de sementes florestais, como as de ucuúba (Virola surinamensis) (Limas et al., 2007), cariru (Talinum triangulare) (Brasileiro et al., 2010) e coroade-frade (Melocactus violaceus) (Zamith et al., 2013). 
No entanto, diante da elevada diversidade das espécies florestais brasileiras com potencial econômico, ainda há muito a ser investigado. Quanto ao guanandi, apesar de haver grande interesse na comercialização de sementes e mudas (Lisboa et al., 2012), são poucas as pesquisas voltadas para a obtenção de alternativas viáveis e práticas para a germinação rápida de suas sementes, que é o principal problema para a produção de mudas.

As sementes de guanandi apresentam comportamento recalcitrante (Vásquez-Carballo et al., 2004), e a manutenção de sua viabilidade ao longo do tempo é limitada. A dormência das sementes dificulta ainda mais o seu manejo e o seu aproveitamento, já que inviabiliza a obtenção de resultados rápidos nos testes laboratoriais das sementes, indispensáveis para o seu comércio. Esse atraso na obtenção dos resultados prejudica a comercialização, pois os testes podem não mais representar a real qualidade das sementes, em razão da perda de sua viabilidade no armazenamento, durante a espera pelos resultados.

A dormência física e mecânica das sementes de guanandi é imposta pela estrutura rígida que evolve o embrião. Segundo Baskin \& Baskin (1996), a dormência física é decorrente de impedimentos externos à entrada de água no embrião, enquanto a dormência mecânica está associada à restrição ao crescimento do embrião. Em ambos os casos, uma vez eliminadas as barreiras, o embrião está fisiologicamente preparado para retomar seus processos metabólicos e germinar. Nery et al. (2007) verificaram que sementes de guanandi germinam mais rápido com a retirada do envoltório. Contudo, esses processos ainda carecem de maior investigação, principalmente quanto às formas de preparo das sementes, para que se possa superar a dormência eficientemente.

Além disso, é importante que se conheçam bem as melhores condições para a germinação das sementes de guanandi. $\mathrm{O}$ substrato e a temperatura interferem diretamente na germinação, por disponibilizar água e aeração em proporção adequada, e por propiciar maior velocidade de embebição e germinação, respectivamente (Stockman et al., 2007; Carvalho \& Nakagawa, 2012). O domínio de melhores técnicas para a germinação é fundamental para embasar as avaliações de laboratório e impulsionar a comercialização das sementes de guanandi.

O objetivo deste trabalho foi avaliar diferentes tipos de preparo de sementes de guanandi, com vistas à superação da dormência física e mecânica, e verificar a influência da temperatura e do substrato sobre a germinação.

\section{Material e Métodos}

O trabalho foi realizado no período de outubro de 2012 a abril de 2013, com sementes coletadas de matrizes de guanandi localizadas em áreas naturais da Mata Atlântica, no Estado do Paraná, nos municípios de Antonina $\left(25^{\circ} 22^{\prime} \mathrm{S}, 48^{\circ} 46^{\prime} \mathrm{W}\right)$, Matinhos $\left(25^{\circ} 47^{\prime} \mathrm{S}\right.$, $\left.48^{\circ} 31^{\prime} \mathrm{W}\right)$ e Pontal do Paraná $\left(25^{\circ} 35^{\prime} \mathrm{S}, 48^{\circ} 33^{\prime} \mathrm{W}\right)$. O clima da região, conforme a classificação de Köppen (Caviglione et al., 2000), é do tipo Cfa, subtropical, com verões quentes e chuvosos, baixa frequência de geadas e sem estação seca definida, com temperaturas médias de $18^{\circ} \mathrm{C}$ nos meses mais frios e de $22^{\circ} \mathrm{C}$ nos mais quentes.

A coleta dos frutos nas árvores foi feita com auxílio de foice pequena de cabo longo (Figura $1 \mathrm{~A}$ ), durante outubro e novembro de 2012, que é o período em que se observa o início da queda das sementes, na região.

Após a coleta, os frutos foram despolpados com auxílio de estilete (Figura $1 \mathrm{~B}$ ), e as sementes foram imersas em solução de detergente neutro (cinco gotas por $100 \mathrm{~mL}$ de água), durante $5 \mathrm{~min}$. Em seguida, as sementes foram lavadas em água corrente, e os resíduos da polpa ainda presente foram retirados com auxílio de esponja (Figura $1 \mathrm{C}$ ). Após novo enxágue, as sementes foram colocadas para secar sobre papel por 48 horas, em ambiente com temperatura controlada $\left(20^{\circ} \mathrm{C}\right)$. Após este período, um lote de sementes foi acondicionado em sacos de papel do tipo Kraft, envolvidos em sacos de plástico, e armazenado em refrigerador $\left(5-10^{\circ} \mathrm{C}\right.$ e $35-45 \%$ de umidade relativa) durante a realização dos testes com as demais sementes.

Para a determinação do teor de água, uma amostra de sementes foi cortada em fragmentos menores que $7 \mathrm{~mm}$. Em seguida, os fragmentos foram homogeneizados e divididos em duas repetições com peso equivalente ao de cinco sementes inteiras. As repetições foram, então, acondicionadas em cápsulas cilíndricas de alumínio previamente pesadas e colocadas para secar em estufa a $103 \pm 2^{\circ} \mathrm{C}$, por $17 \pm 1$ hora (Regras para análise de sementes, 2009).

A curva de embebição das sementes foi realizada com duas repetições de 15 sementes, para cada um dos seguintes tipos de preparo: sementes íntegras 

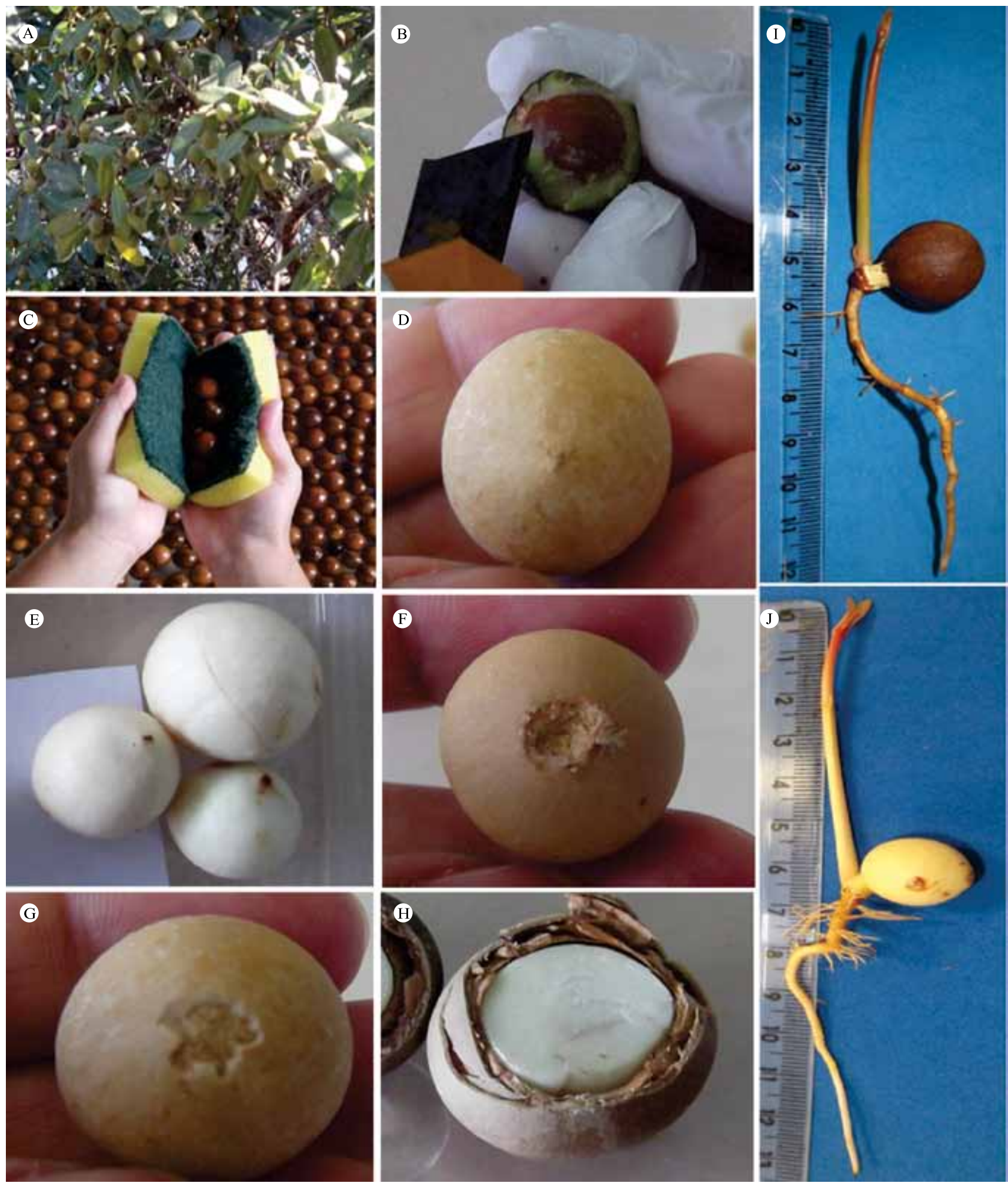

Figura 1. Ramos de guanandi (Calophyllum brasiliense) com frutos (A); remoção da polpa do fruto (B); lavagem das sementes (C); sementes íntegras (D); sementes nuas, sem endocarpo ou tegumento (E); sementes com punctura no endocarpo, na região próxima ao eixo embrionário $(\mathrm{F})$; semente com punctura no endocarpo, na região oposta ao eixo embrionário $(\mathrm{G})$; semente cortada a $1 / 3$ da região oposta ao eixo embrionário $(\mathrm{H})$; plântula normal, oriunda de sementes íntegras (I); e plântula normal, oriunda de sementes nuas $(\mathrm{J})$. 
(Figura 1 D); sementes nuas, sem endocarpo e tegumento (Figura $1 \mathrm{E}$ ); e sementes com punctura no endocarpo, na região próxima ao eixo embrionário (Figura $1 \mathrm{~F}$ ) ou na região oposta ao eixo embrionário (Figura $1 \mathrm{G}$ ). A retirada do endocarpo e do tegumento, bem como a punctura, foi realizada com auxílio de estilete. A hidratação das sementes foi feita entre folhas de papel toalha. Foram utilizadas quatro folhas umedecidas com quantidade de água equivalente a 2,5 vezes a massa do substrato seco.

Durante a hidratação, a mudança na massa das sementes foi acompanhada ao longo do período de embebição. Para tanto, foram realizadas pesagens em intervalos de 3 horas, até completar as nove primeiras horas; após este período, a pesagem ocorreu a cada 24 horas e encerrou-se no momento em que $50 \%$ das sementes emitiram a raiz primária - exceto para as sementes íntegras, cuja avaliação foi encerrada aos 99 dias, quando as sementes não tinham mais condição de emitir raiz em razão do avançado processo de deterioração. Antes de cada pesagem, as sementes foram secas superficialmente em papel toalha. A estimativa da percentagem de água das sementes foi feita de acordo com a seguinte fórmula: $\mathrm{Mf}=(100-$ TAi $) \times(\mathrm{Mi} /(100$ - TAf $))$, em que TAi e TAf representam o teor (\%) de água inicial e final, respectivamente; e Mi e Mf são a massa $(\mathrm{g})$ inicial e final, respectivamente.

O teste de germinação foi realizado em duas etapas. Inicialmente, foram testados os quatro tipos de preparo descritos anteriormente. $O$ teste foi instalado com cinco repetições de 20 sementes cada uma, as quais foram desinfestadas com solução de hipoclorito de sódio (de 1,0 a 1,25\% de cloro ativo), por $5 \mathrm{~min}$. Após a desinfecção, as sementes foram lavadas em água corrente e secas sobre papel, por aproximadamente 10 min. Para a semeadura, as sementes foram enroladas em papel toalha, com quatro folhas de papel umedecidas em água, na quantidade de 2,5 vezes a massa do substrato seco. Os rolos foram envolvidos em sacos de plástico e mantidos em germinador do tipo Mangelsdorf, tendo-se avaliado duas temperaturas de condicionamento: 25 e $30^{\circ} \mathrm{C}$, sem fornecimento de luz.

$\mathrm{Na}$ segunda etapa do teste de germinação, foram avaliados três substratos (papel toalha, areia $\mathrm{e}$ vermiculita) e dois tipos de preparo das sementes: semente nua, sem endocarpo e sem tegumento (Figura $1 \mathrm{E}$ ); e semente cortada a $1 / 3$ da região oposta ao eixo embrionário (Figura $1 \mathrm{H}$ ), tendo-se utilizado dez repetições de 20 sementes para cada tratamento.
O corte da semente foi feito com auxílio de lâmina de aço inox presa a suporte de madeira, com armação semelhante à guilhotina. Para a semeadura em substrato papel, o mesmo procedimento descrito anteriormente foi adotado para cada tratamento. Já para a areia e a vermiculita, a semeadura foi feita com os substratos com umidade na capacidade de campo. Ambos os substratos tinham granulometria média e foram previamente esterilizados em autoclave, a 1 atm e a $120^{\circ} \mathrm{C}$ por 1 hora. As sementes foram colocadas em germinador do tipo Mangelsdorf, a $30^{\circ} \mathrm{C}$, sem fornecimento de luz, tendo-se realizado contagens periódicas da germinação. O critério de avaliação para os tratamentos foi a percentagem de plântulas normais que eles proporcionaram. Consideraram-se normais as plântulas com a presença de raiz primária e parte aérea com o primeiro par de folhas evidente (Figura $1 \mathrm{I}$ e J).

$\mathrm{O}$ vigor das sementes foi avaliado pelo índice de velocidade de germinação (IVG) - determinado ao longo do teste de germinação, de acordo com Maguire (1962) - e pelo índice de velocidade de emergência (IVE) - obtido em casa de vegetação, com dez repetições de 20 sementes para cada tratamento, com as sementes distribuídas em caixas de plástico (40x30x15 cm), semeadas em areia e mantidas com irrigação diária. As avaliações foram feitas a cada sete dias, a partir da emergência das primeiras plântulas, e encerraram-se com a estabilização da emergência.

Utilizou-se o delineamento inteiramente casualizado, em arranjo fatorial $2 \times 4$, na etapa inicial do teste de germinação (temperaturas $\mathrm{x}$ preparo das sementes), e em arranjo fatorial $3 \times 2$, na segunda etapa do teste (substrato x preparo das sementes). Os dados foram submetidos à análise de variância, e as médias foram comparadas pelo teste de Tukey, a 5\% de probabilidade. A curva de hidratação e os dados do teor de água inicial não foram submetidos a tratamento estatístico.

\section{Resultados e Discussão}

O teor de água inicial das sementes, antes da instalação dos testes de germinação e de vigor, foi de $35 \%$. Para a realização da curva de hidratação, o teor foi de 33,4\%. Esses valores são normais para sementes recalcitrantes, que mantêm o teor de água entre $30 \mathrm{e}$ 70\% (Marcos Filho, 2005).

Na primeira parte do estudo do teste de germinação, observou-se melhor resultado quando as sementes estavam totalmente livres de impedimentos físicos 
(Tabela 1), sem endocarpo e tegumento, com $72 \%$ de germinação, independentemente da temperatura utilizada $\left(25\right.$ ou $\left.30^{\circ} \mathrm{C}\right)$. A germinação foi muito menor (23\%) quando sementes íntegras (testemunha) foram utilizadas. Nos tratamentos com punctura no endocarpo, a germinação esteve entre 50 e $57 \%$ (31\% maior que na testemunha, em média), ainda bastante inferior à observada com sementes nuas. Em contraste com esses resultados, Nery et al. (2007) não relataram diferenças na germinação de sementes de guanandi íntegras e sem tegumento; no entanto, os autores não utilizaram o critério de plântula normal para avaliação do teste, e sim a emissão de raiz primária e a presença de parte aérea com $5 \mathrm{~mm}$ de comprimento. Nesse caso, os resultados precoces podem ter superestimado a germinação das sementes íntegras. No presente trabalho, com esse mesmo comprimento da parte aérea, ainda não era possível observar a expansão das folhas primárias, que é um requisito necessário para caracterizar plântulas normais (Regras para análise de sementes, 2009).

A retirada do endocarpo e do tegumento é um procedimento moroso, de difícil execução em razão da estrutura rígida do envoltório das sementes. Entretanto, o preparo de sementes nuas foi muito vantajoso em relação aos demais, não somente por ter aumentado a percentagem de germinação, mas, também, pela rapidez do processo germinativo, uma vez que o IVG também foi superior com a retirada do envoltório (Tabela 1), especialmente para a temperatura de $30^{\circ} \mathrm{C}$. Portanto, são necessários mais estudos com procedimentos para facilitar a retirada do envoltório

Tabela 1. Germinação e índice de velocidade de germinação de sementes de guanandi (Calophyllum brasiliense) em substrato papel, de acordo com duas temperaturas de incubação e quatro tipos de preparo da semente ${ }^{(1)}$.

\begin{tabular}{lccccc}
\hline Temperatura & $\begin{array}{c}\text { Semente } \\
\text { íntegra }\end{array}$ & $\begin{array}{c}\text { Semente } \\
\text { nua }\end{array}$ & $\begin{array}{c}\text { Punctura } \\
\text { oposta } \\
\text { ao eixo }\end{array}$ & $\begin{array}{c}\text { Punctura } \\
\text { na região } \\
\text { do eixo }\end{array}$ & Média \\
\hline \multicolumn{5}{c}{ Germinação (\%) } \\
$25^{\circ} \mathrm{C}$ & 27 & 72 & 53 & 50 & $51 \mathrm{a}$ \\
$30^{\circ} \mathrm{C}$ & 18 & 72 & 54 & 57 & $50 \mathrm{a}$ \\
\hline Média & $23 \mathrm{C}$ & $72 \mathrm{~A}$ & $54 \mathrm{~B}$ & $54 \mathrm{~B}$ & \\
$\mathrm{CV}(\%)$ & \multicolumn{5}{c}{27,6} \\
\hline \multicolumn{7}{c}{ Índice de velocidade de germinação } \\
$25^{\circ} \mathrm{C}$ & $0,06 \mathrm{aB}$ & $0,34 \mathrm{bA}$ & $0,13 \mathrm{aB}$ & $0,13 \mathrm{aB}$ & - \\
$30^{\circ} \mathrm{C}$ & $0,05 \mathrm{aC}$ & $0,54 \mathrm{aA}$ & $0,19 \mathrm{aB}$ & $0,20 \mathrm{aB}$ & - \\
\hline $\mathrm{CV}(\%)$ & \multicolumn{5}{c}{35,54} \\
\hline
\end{tabular}

(1)Médias seguidas de letras iguais, maiúsculas nas linhas e minúsculas nas colunas, não diferem pelo teste de Tukey, a 5\% de probabilidade. das sementes de guanandi. Brancalion et al. (2010), ao avaliarem 272 espécies arbóreas nativas, observaram que a temperatura de $25^{\circ} \mathrm{C}$ é a mais indicada para a germinação de espécies do Cerrado e da Mata Atlântica, e a de $30^{\circ} \mathrm{C}$, para as espécies do bioma Amazônia. A temperatura de $30^{\circ} \mathrm{C}$ é a recomendada para várias espécies nativas, como ucuúba (Limas et al., 2007), murta (Blepharocalyx salicifolius) (Rego et al., 2009) e faveira (Dimorphandra mollis) (Pacheco et al., 2010).

Os resultados da curva de embebição das sementes confirmam o efeito vantajoso do preparo com sementes nuas e com punctura do endocarpo, independentemente da região (Figura 2). A absorção de água necessária para a emissão da raiz primária foi aproximadamente 7 e $13 \%$ menor nas sementes nuas do que nas sementes com punctura e íntegras, respectivamente. Além disso,
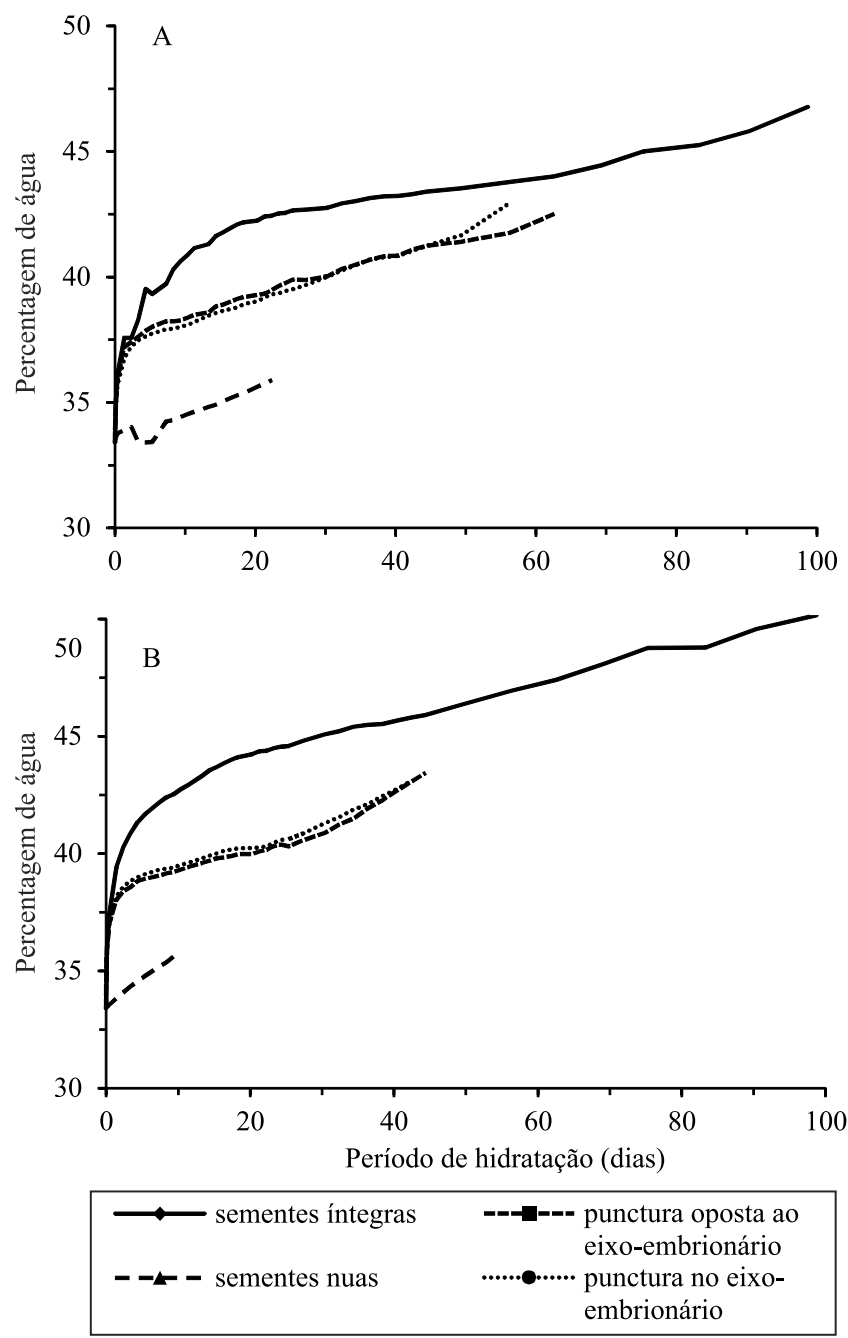

Figura 2. Curva de embebição de sementes de guanandi (Calophyllum brasiliense): A, hidratação a $25^{\circ} \mathrm{C}$; B, hidratação a $30^{\circ} \mathrm{C}$. 
com o teor de água de $35,8 \%$, metade das sementes nuas já havia emitido raiz, tanto na temperatura de $25^{\circ} \mathrm{C}$ quanto na de $30^{\circ} \mathrm{C}$. Essa umidade representa um aumento de apenas $2,4 \%$ em relação à umidade inicial. Contudo, com a temperatura de $30^{\circ} \mathrm{C}$, somente foram necessários cerca de dez dias, metade do tempo requerido para atingir a mesma umidade com a temperatura de $25^{\circ} \mathrm{C}$. O menor tempo de hidratação com a germinação a $30^{\circ} \mathrm{C}$ ocorre pela diminuição na viscosidade da água e pelo aumento na sua energia cinética (Marcos Filho, 2005).

Sementes recalcitrantes são liberadas da planta mãe com alto teor de água, quase com a umidade necessária para iniciar a germinação. Liu et al. (2005) trabalharam com Garcinia cowa, uma espécie recalcitrante que apresenta envoltórios semelhantes ao do guanandi, e constataram baixa absorção de água das sementes até o início da germinação, principalmente quando estas estavam livres do revestimento restritivo. Limas et al. (2007) observaram o mesmo comportamento em sementes de ucuúba, espécie recalcitrante, que ganhou menos de 5\% de água após 72 horas de hidratação. $O$ incremento de umidade também foi pequeno para sementes recalcitrantes de Quercus rugosa: apenas $8,2 \%$ após 400 horas de hidratação (Castro-Colina et al., 2012). Entretanto, espécies ortodoxas tendem a uma expressiva absorção de água após a embebição, como constatado em pinhãomanso (Jatropha curcas), cujas sementes absorvem mais de cinco vezes a quantidade inicial água $(7,5 \%)$ em 24 horas de embebição, e alcançam o teor de $43 \%$ (Braga et al., 2012).

A curva de embebição das sementes de guanandi seguiu o padrão trifásico descrito por Bewley \& Black (1978), exceto no tratamento de sementes nuas. De acordo com esse padrão, a fase I é caracterizada por rápida absorção de água; a fase II, pela redução da embebição e da taxa respiratória; e a fase III, pela retomada da absorção de água e pelo crescimento do embrião, evidenciado pela protrusão da raiz primária. Para sementes nuas, essas três fases de hidratação não ficaram nítidas (Figura 2), principalmente na temperatura de $30^{\circ} \mathrm{C}$, em que as sementes apresentaram aumento constante no teor de água até a protrusão da raiz. $\mathrm{O}$ não impedimento da entrada de água e o crescimento livre do eixo embrionário com a remoção do envoltório da semente proporcionaram, portanto, absorção de água e desenvolvimento embrionário contínuos.

Liu et al. (2005) relataram que as sementes nuas de G. cowa exibem embebição constante, sem padrão definido, e absorvem menor quantidade de água que as sementes intactas da espécie, que seguem o padrão trifásico. Cabe destacar que o início de uma fase não implica a paralisação das anteriores (Marcos Filho, 2005); dessa forma, a simultaneidade pode ter interferido sensivelmente na curva de embebição observada nas sementes nuas.

Assim, a estrutura rígida que envolve o embrião do guanandi exerce impedimento físico, que restringe a entrada de água e a protrusão da raiz primária, o que caracterizaria dormência física e mecânica, respectivamente (Baskin \& Baskin, 1996). As estruturas de resistência à entrada de água consistem em uma estratégia de dormência que permite a germinação das sementes de forma desuniforme no tempo (Carvalho \& Nakagawa, 2012). Desse modo, como o guanandi ocorre preferencialmente em regiões alagadas (Schultz, 2011), a estrutura de sua semente provavelmente é uma importante estratégia de sobrevivência e perpetuação da espécie. Normalmente, a superação da dormência física pode ser promovida pela ação de fatores que degradam ou enfraquecem o envoltório da semente, como, por exemplo, a ação de microrganismos (Baskin \& Baskin, 1996).

O comportamento de embebição das sementes sugere que a presença do endocarpo e do tegumento não restringiu totalmente a entrada de água (Figura 2), mas exigiu maior tempo de embebição para que o embrião atingisse a hidratação suficiente para iniciar a germinação: 30-40 dias a mais para sementes com puncturas, e 80-90 dias a mais para sementes íntegras. Segundo Liu et al. (2005), o fato de sementes intactas absorverem maior quantidade de água não garante que esta entre em contato com o embrião, uma vez que ela fica retida no envoltório.

Não houve interação entre o substrato e o tipo de preparo das sementes sobre a germinação. No entanto, esses fatores afetaram isoladamente o poder germinativo das sementes (Tabela 2). O papel foi o substrato mais adequado para a germinação, apesar de não ter diferido significativamente da vermiculita. As sementes nuas também apresentaram melhor desempenho que as que sofreram apenas a remoção parcial do envoltório. 
O papel é um dos substratos mais indicados para a condução do teste de germinação, de acordo com as Regras para Análise de Sementes (Regras para análise de sementes, 2009). Seu manejo é prático e ele otimiza a ocupação de espaço nos equipamentos, além de contribuir para a manutenção da limpeza no laboratório. Porém, conforme ressaltam Pacheco et al. (2006), ainda são escassas as recomendações para espécies florestais. Para sementes de ipê-branco (Tabebuia roseo-alba), recomenda-se a combinação de substrato papel e temperatura de $30^{\circ} \mathrm{C}$ (Stockman et al., 2007); já para sementes de murta, os substratos papel, areia e vermiculita apresentaram resultados satisfatórios (Rego et al., 2009).

Houve interação entre os fatores na avaliação do vigor das sementes, e as sementes nuas apresentaram maiores valores de IVE que as cortadas e melhor desempenho no substrato areia (Tabela 2).

Quando a emergência e o IVE foram avaliados em casa de vegetação, as sementes nuas novamente tiveram comportamento superior ao das cortadas (Tabela 3 ).

$\mathrm{Na}$ avaliação da distribuição da germinação ao longo do tempo, observou-se que os substratos papel, areia e vermiculita apresentaram, respectivamente, 57, 86

Tabela 2. Germinação e índice de velocidade (IV) de germinação de acordo com diferentes substratos e preparos da semente (nuas e cortadas) de guanandi (Calophyllum brasiliense $)^{(1)}$.

\begin{tabular}{lcccccc}
\hline \multirow{2}{*}{ Substrato } & \multicolumn{2}{c}{ Germinação } & Média & \multicolumn{2}{c}{ IV de germinação } \\
\cline { 2 - 3 } \cline { 2 - 3 } & Nuas & Cortadas & & & Nuas & Cortadas \\
\hline Papel & 88 & 68 & & $78 \mathrm{a}$ & $0,71 \mathrm{bA}$ & $0,42 \mathrm{aB}$ \\
Areia & 82 & 54 & $68 \mathrm{~b}$ & $0,85 \mathrm{aA}$ & $0,41 \mathrm{aB}$ \\
Vermiculita & 79 & 67 & $73 \mathrm{ab}$ & $0,71 \mathrm{bA}$ & $0,53 \mathrm{aB}$ \\
\hline Média & $83 \mathrm{~A}$ & $63 \mathrm{~B}$ & - & - & - \\
CV $(\%)$ & \multicolumn{2}{c}{15,86} & & \multicolumn{2}{c}{18,83} \\
\hline
\end{tabular}

${ }^{(1)}$ Médias seguidas de letras iguais, maiúsculas nas linhas e minúsculas nas colunas, não diferem pelo teste de Tukey, a 5\% de probabilidade.

Tabela 3. Emergência e índice de velocidade (IV) de emergência de plântulas de guanandi (Calophyllum brasiliense) de acordo com diferentes preparos da semente ${ }^{(1)}$.

\begin{tabular}{lcc}
\hline Preparo & Emergência (\%) & IV de emergência \\
\hline Sementes nuas & $81 \mathrm{a}$ & $0,56 \mathrm{a}$ \\
Sementes cortadas & $67 \mathrm{~b}$ & $0,33 \mathrm{~b}$ \\
\hline $\mathrm{CV}(\%)$ & 18,77 & 18,58 \\
\hline${ }^{(1)}$ Médias seguidas de letras iguais não diferem pelo teste de Tukey, a 5\% \\
de probabilidade.
\end{tabular}

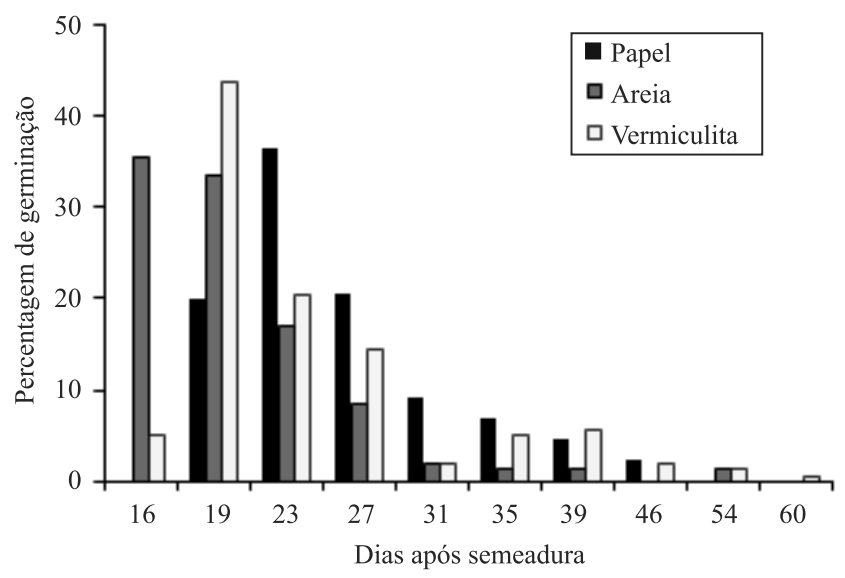

Figura 3. Distribuição da germinação de sementes nuas de guanandi (Calophyllum brasiliense) durante teste de germinação a $30^{\circ} \mathrm{C}$.

e $69 \%$ de sementes nuas germinadas, após 23 dias da semeadura (Figura 3). Aos 31 dias após a semeadura, estas percentagens subiram para 88, 96 e 85\%. Esses resultados são indicativos de que o substrato areia proporcionou maior rapidez e uniformidade à germinação, tendo sido possível realizar a primeira contagem no vigésimo dia após a semeadura; porém, a contagem final com esse substrato somente foi possível aos 54 dias. Com o papel, a primeira contagem foi aos 30 dias após a semeadura, mas esse substrato permitiu o encerramento do teste aos 46 dias, oito dias antes da areia e 11 dias antes da vermiculita. Assim, como o papel é o substrato mais empregado nos laboratórios de análise de sementes e apresenta resultados satisfatórios em relação aos demais, seu uso também pode ser recomendado para testes de germinação e de avaliação do vigor de sementes de guanandi.

\section{Conclusões}

1. A remoção total do envoltório (endocarpo e tegumento) das sementes de guanandi (Calophyllum brasiliense) permite a completa superação das dormências física e mecânica.

2. A germinação das sementes deve ser realizada em substrato papel, à temperatura de $30^{\circ} \mathrm{C}$.

\section{Agradecimentos}

À Coordenação de Aperfeiçoamento de Pessoal de Nível Superior (Capes), pelas bolsas de estudo. 


\section{Referências}

BASKIN, C.C.; BASKIN, J.M. Seeds: ecology, biogeography, and evolution of dormancy and germination. San Diego: Academic Press, 1996. 666p.

BERNABÉ-ANTONIO, A.; ESTRADA-ZÚÑIGA, M.E.; BUENDÍA-GONZÁLEZ, L.; REYES-CHILPA, R.; CHÁVEZÁVILA, V.M.; CRUZ-SOSA, F. Production of anti-HIV-1 calanolides in a callus culture of Calophyllum brasiliense (Cambes). Plant Cell, Tissues and Organ Culture, v.103, p.3340, 2010. DOI: 10.1007/s11240-010-9750-4.

BEWLEY, J.D.; BLACK, M. Physiology and biochemistry of seeds in relation to germination: volume 1: development, germination, and growth. New York: Springer Berlin Heidelberg, 1978. v.1, 306p. DOI: 10.1007/978-3-642-66668-1.

BRAGA, F.C.; SERRA, C.P.; VIANA JUNIOR, N.S.; OLIVEIRA, A.B.; CORTES, S.F.; LOMBARDI, J.A. Angiotensin-converting enzyme inhibition by Brazilian plants. Fitoterapia, v.78, p.353358, 2007. DOI: 10.1016/j.fitote.2007.02.007.

BRAGA, N. da S.; MORAIS, C.S.B. de; ROSSETO, C.A.V. Hidratação controlada de sementes de pinhão manso. Revista Ciência Agronômica, v.43, p.589-597, 2012. DOI: 10.1590/ S1806-66902012000300023.

BRANCALION, P.H.S.; NOVEMBRE, A.D. da L.C.; RODRIGUES, R.R. Temperatura ótima de germinação de espécies arbóreas brasileiras. Revista Brasileira de Sementes, v.32, p.1521, 2010. DOI: 10.1590/S0101-31222010000400002.

BRASILEIRO, B.G.; DIAS, D.C.F.S.; CASALI, V.W.D.; BHERING, M.C.; CECON, P.R. Effects of temperature and pre-germinative treatments on seed germination of Talinum triangulare (Jacq.) willd (Portulacaceae). Revista Brasileira de Sementes, v.32, p.151-157, 2010. DOI: 10.1590/S010131222010000400017 .

CARVALHO, H. de O.; MEDEIROS, B.J.L.; SÁ, B.M. de; ARAÚJO, J.T.C. de; KAWAKAMI, M.Y.M.; FAVACHO, H.A.S.; CARVALHO, J.C.T. Study of dissolution profiles and desintegration of capsules containing the dried hydroethanolic extract of Calophyllum brasiliense. Revista Brasileira de Farmacognosia, v.23, p.194-199, 2013. DOI: 10.1590/S0102$695 \times 2012005000145$.

CARVALHO, M.N. de; NAKAGAWA, J. Sementes: ciência, tecnologia e produção. 5.ed. Jaboticabal: Funep, 2012. 590p.

CASTRO-COLINA, L.; MARTÍNEZ-RAMOS, M.; SÁNCHEZCORONADO, M.E.; HUANTE, P.; MENDONZA, A.; OROZCOSEGOVIA, A. Effect of hydropriming and acclimation treatments on Quercus rugosa acorns and seedlings. European Journal of Forest Research, v.131, p.747-756, 2012. DOI: 10.1007/s10342011-0548-7.

CAVIGLIONE, J.H.; KIIHL, L.R.B.; CARAMORI, P.H.; OLIVEIRA, D. de. Cartas climáticas do Paraná. Londrina: Iapar, 2000. Disponível em: <http:/www.iapar.br/modules/conteudo/ conteudo.php?conteudo $=677>$. Acesso em: 20 nov. 2013 .

LIMAS, J.D.; SILA, B.M. da S.; MORAES, W. da S. Germinação e armazenamento de sementes de Virola surinamensis (Rol.)
Warb. (Myristicaceae). Revista Árvore, v.31, p.37-42, 2007. DOI: 10.1590/S0100-67622007000100005.

LISBOA, A.C.; SANTOS, P.S. dos; OLIVEIRA NETO, S.N. de; CASTRO, D.N. de; ABREU, A.H.M. de. Efeito do volume de tubetes na produção de mudas de Calophyllum brasiliense e Toona ciliata. Revista Árvore, v.36, p.603-609, 2012. DOI: 10.1590/ S0100-67622012000400003.

LIU, Y.; QIU, Y.P.; ZHANG, L.; CHEN, J. Dormancy breaking and storage behavior of Garcinia cowa Roxb. (Guttiferae) seeds: implications for ecological function and germplasm conservation. Journal of Integrative Plant Biology, v.47, p.38-49, 2005. DOI: 10.1111/j.1744-7909.2005.00010.x.

MAGUIRE, J.D. Speed of germination - aid in selection and evaluation for seedling emergence and vigor. Crop Science, v.2, p.176-177, 1962. DOI: 10.2135/cropsci1962.0011183X00020002 $0033 x$.

MARCOS FILHO, J. Fisiologia de sementes de plantas cultivadas. Piracicaba: Fealq, 2005. 495p.

NERY, F.C.; ALVARENGA, A.A. de; JUSTO, C.F.; DOUSSEAU, S.; VIEIRA, C.V. Efeito da temperatura e do tegumento na germinação de sementes de Calophyllum brasiliense. Ciência e Agrotecnologia, v.31, p.1872-1877, 2007. DOI: 10.1590/S141370542007000600041 .

NOLDIN, V.F.; ISIAS, D.B.; CECHINEL FILHO, V. Gênero Calophyllum: importância química e farmacológica. Nova Química, v.29, p.549-554, 2006. DOI: 10.1590/S010040422006000300025 .

OLIVEIRA, V.C. de; JOLY, C.A. Flooding tolerance of Calophyllum brasiliense Camb. (Clusiaceae): morphological, physiological and growth response. Trees, v.24, p.185-193, 2010. DOI: 10.1007/s00468-009-0392-2.

PACHECO, M.V.; MATOS, V.P.; FERREIRA, R.L.C.; FELICIANAO, A.L.P.; PINTO, K.M.S. Efeito de temperaturas e substratos na germinação de sementes de Myracrodruon urundeuva Fr. All. (Anacardiaceae). Revista Árvore, v.30, p.359-367, 2006. DOI: $10.1590 / \mathrm{S} 0100-67622006000300006$.

PACHECO, M.V.; MATTEI, V.L.; MATOS, V.P.; SENA, L.H.M. Germination and vigor of Dimorphandra mollis Benth. seeds under different temperature and substrates. Revista Árvore, v.34, p.205213, 2010. DOI: 10.1590/S0100-67622010000200002.

REGO, S.S.; NOGUEIRA, A.C.; KUNIYOSHI, Y.S.; SANTOS, Á.F. dos. Germinação de sementes de Blepharocalyx salicifolius (H.B.K.) Berg. em diferentes substratos e condições de temperaturas, luz e umidade. Revista Brasileira de Sementes, v.31, p.212-220, 2009. DOI: 10.1590/S010131222009000200025 .

REGRAS para análise de sementes. Brasília: Ministério da Agricultura, Pecuária e Abastecimento, 2009. 395p.

SCHULTZ, J. Calophyllum brasiliense: Olandi. In: CORADIN, L.; SIMINSKI, A.; REIS, A. Espécies nativas da flora brasileira de valor econômico atual ou potencial: plantas para o futuro - Região Sul. Brasília: Ministério do Meio Ambiente, 2011. p.440-443.

STOCKMAN, A.L.; BRANCALION, P.H.S.; NOVEMBRE, A.D. da L.C.; CHAMMA, H.M.C.P. Sementes de ipê-branco 
(Tabebuia roseo-alba (Ridl.) Sand. - Bignoniaceae): temperatura e substrato para o teste de germinação. Revista Brasileira de Sementes, v.29, p.139-143, 2007. DOI: 10.1590/S010131222007000300016 .

VÁSQUEZ-CARBALLO, W.; THOMSEN, K.A.; JØKER, D. Desiccation and storage of seeds of Astronium graveolens and Calophyllum brasiliense, two native species of Costa Rica. In: SACANDÉ, M.; JØKER, D.; DULLOO, M.E.; THOMSEN,
K.A. Comparative storage biology of tropical tree seeds. Rome: International Plant Genetic Resources Institute, 2004. p.285-294.

ZAMITH, L.R.; CRUZ, D.D.; RICHERS, B.T. The effect of temperature on the germination of Melocactus violaceus Pfeiff. (Cactaceae), a threatened species in restinga sandy coastal plain of Brazil. Anais da Academia Brasileira Ciências, v.85, p.615-622, 2013. DOI: 10.1590/S0001-37652013000200010.

Recebido em 17 de março de 2014 e aprovado em 5 de setembro de 2014 